side is contracted and empty; all the valves normal. Lungs.-Right lung free from adhesions, somewhat congested; crepitant throughout on section; weight nineteen ounces. Left lung adherent by lower lobe posteriorly and to diaphragm; weight sixteen ounces. Bronchi in both lungs normal.

The hair-pin had probably been swallowed some time previously, as there was no trace of irritation in the stomach.

Influgnce of Traumatism on Mental Affections.

Dr. A. VAlLfer reports the following case:-L. T-, æt. 62, admitted to the Quebec Asylum 12th March, 1894, suffering for the last five months from a severe attack of melancholia, brought on by pecuniary troubles and alcoholic excesses. Believing himself to be damned for ninety-nine years, he kept perfect silence. Nothing could distract him for a moment, and he opposed a passive resistance to all our endeavours. His general health gradually gave way under the influence of melancholia, complicated by insomnia and sitiophobia, and he was sent to the infirmary.

May 3 rd.- I was called to extract a foreign body which he had thrust into his eye. He was sitting on his bed quite silent. A black spot was noticed at the internal angle of the right eye. It was the head of a nail four inches long, and was at once extracted. Alarming symptoms soon appeared : face very pale, extremities cold, pulse filiform, left arm and leg paralysed.

May 4th.-He rallied a little, but the hemiplegia continued.

May 5th.-Partial convulsions set in over the face, lips, neck, and left arm. They lasted about twenty-four hours.

May 8th.-Hemiplegia disappearing; mental state improving.

After three or four days all the nervous symptoms have disappeared except a divergent strabismus of the right eye, which lasted about fifteen days. The general health and the mental condition continued to improve gradually till, at the end of May, he was able to walk round the asylum by himself. His memory was perfectly good, but he does not know why he thrust the nail in his eye. On the 15th of July he left the asylum perfectly recovered.

Another case where traumatism hastened recovery occurred here a few years ago. O. R-, æt. 25, admitted suffering from a violent attack of acute mania. A few weeks after his admission he quarrelled with another patient, and was bitten very severely on the thumb. Intense nervous tremors set in, and lasted for an hour. Thereafter $\mathrm{O}$. $\mathrm{R}$ - became conscious, made a rapid recovery, and was discharged in a few days.

\title{
RECENT MEDICO-LEGAL CASES
}

RePorted BY Dr. MERCIER.

[The editors request that members will oblige by sending full newspaper reports of all cases of interest as published by the local press at the time of the assizes.]

$$
\text { Reg. v. Bryson. }
$$

John Bryson, an elderly man, was indicted for the murder of a woman with several aliases. The murder was a peculiarly brutal one, the woman's head being battered into a shapeless mass, both eyes destroyed, and the face rendered unrecog. nisable. No evidence of provocation is reported. The prisoner had been drinking a good deal just before the murder, and when arrested immediately after was much the worse for drink. It was proved that he had had a sunstroke, and had narrowly escaped being killed by lightning, and that since these experiences he had been subject, especially when in drink, to outbreaks of unprovoked violence, of which he appeared afterwards to have no recollection. Several such outbreaks were described by witnesses. The prisoner, by advice of his counsel, pleaded guilty of culpable homicide. Sentence was delayed until the afternoon, when the judge stated that after consultation with his colleague he had been able to decide to treat the prisoner in a comparatively lenient manner.-Ten years' penal servitude.-(The Lord Justice's Clerk.)-Scotsman, August 3 1st.

A fresh instante of the growing practice of considering the mental condition of the convict in awarding punishment. The prisoner was allowed to plead guilty of 
homicide merely, and sentence was mitigated in consideration of the state of his mind.

Reg. v. Truett.

Charles Truett, 60 , labourer, was indicted for the murder of his sister-in-law. Prisoner walked into the home of the deceased and stabbed her with a long knife, inflicting a wound of which she died. Shortly after he said, "Revenge is sweet. I don't care if I hang, as long as she dies." It was proved that the prisoner had long had an erroneous belief that his father's property had been unequally divided, and that the deceased was responsible for the unequal division. At the police station he was noticed to be very strange in his manner, and it was shown by the prosecution that he had long been regarded as not responsible for his actions.-Guilty, but insane.-Central Criminal Court, July 28th (Mr. Justice Lawrence).-Times. July 29th.

This case illustrates once more several very common occurrences. The evidence showed clearly that the prisoner knew the nature and quality of his act, and knew that it was wrong. Yet he was found insane. Evidence of insanity was furnished by the prosecution. And it is a fresh instance of the commission of a serious crime by a man who had long been known to be insane, and who ought not to have been at large.

\section{Reg. v. Copeland.}

Prisoner, a woman 2 t. 28 , was found lying in three feet of water with a child under each arm. She was restored, but the children were dead. On being rescued she said that "she had been put about, and didn't know what to do with herself. She had had no sleep all night, she was very ill, and her husband was angry with her." It was proved that she was much weakened by illness and recent operations, and it was suggested that her mind had thereby become affected.-Guilty, but insane.-Stafford Assizes, July 26th (Mr. Justice Channell). - Times, July 27th.

There was no evidence of insanity except the act itself and the inadequacy of the motive; yet an unquestionably just verdict was given.

$$
\text { Reg. v. Viney. }
$$

William Viney, 72, labourer, was indicted for the murder of three of his children and the attempted murder of a fourth. Prisoner, who had been at one time well off, but had sunk to the position of a hawker, and who had been deserted by his wife, took his five children to Leyton marshes, and there cut the throats of four of them, killing three and seriously injuring the fourth, while the fifth ran away. It was proved that some time before, the prisoner had been considered unsound in mind. Dr. Scott said that the prisoner was of weak mind, but he could not certify him as insane at the present time. The prisoner had told him that a power of darkness came over him, and he thought it right to kill the children, so that they might go to a better world. The jury found a verdict of guilty, but said that there were extenuating circumstances, and strongly recommended the prisoner to mercy.-Central Criminal Court, September $15^{\text {th }}$ (Mr. Justice Darling).-Times, September 16th.

A case very similar to that of Copeland (supra), but with decidedly stronger evidence of insanity. Yet Copeland was found insane, and Viney was not. Clearly one of those verdicts was wrong. Are we then to blame the law? Scarcely. Under the same law that condemned Viney, Copeland was found insane. It was not the law, therefore, that required the condemnation of Viney. The discrepancy is to be found in the fact that the judges were different, the counsel different, and the juries different. So long as the personal element in trials remains, so long will there be a discrepancy in verdicts. But in spite of the differences in the verdicts, the fate of the convicts will be the same, and thus the personal variation is rectified.

$$
\text { Reg. v. J. A. Campbell. }
$$

Prisoner was the Superintendent of the Garlands Asylum, and was charged with the offence, under the Lunacy Act, 1890, of having intercourse or attempting to have intercourse with a female patient under his care. The facts were undisputed, and the plea of insanity was raised. It was proved that the prisoner had for years been habitually intoxicated, and that for months past he had rendered 
himself conspicuous by habits of absurd braggadocio, which led those with whom he associated to regard him as insane, and as subject to delusions of grandeur. The offence was committed with scarcely any precautions in the way of concealment, and was of a nature that, considering the position and the age of the prisoner, of itself suggested insanity. On the other hand, it was proved that even up to the time of the offence the prisoner was capable of transacting difficult business in a thoroughly efficient manner.-Guilty, but insane.-Carlisle Assizes, November 4th (Mr. Justice Phillimore).-East Cumberland News, November 5th.

Reg. v. Yeo.

Henry Yeo was indicted for publishing libels concerning Dr. Bevan Lewis, Superintendent of the West Riding Asylum. The prisoner was the editor of a weekly paper called the $S p y$, published at Manchester, and in 1896 , while undergoing a sentence of twelve months' imprisonment for libel, he was transferred from prison to the West Riding Asylum as a criminal lunatic. He appears to have been released at the expiration of his sentence, and subsequently published in his paper a series of articles containing gross libels upon Dr. Bevan Lewis. The prisoner defended himself, and in his address to the jury he alleged that Dr. Lewis, by means of some electrical apparatus or patent process, could tell what he was doing wherever he was. He appealed to the judge to inquire into his persecution and to order an expert to examine the asylum and discover the apparatus by which the persecution had been effected. The jury found the prisoner guilty, and he was sentenced to twelve months' imprisonment. The prisoner's wife, who had assisted in publishing the libels, pleaded guilty to this offence, and in sentencing her the judge said that as her husband was subject to delusions, and could scarcely be held responsible for what he did, she had done very wrong to assist him.-Yorkshire Assizes, August ist (Mr. Justice Grantham).-Times, August 2nd.

Reg. v. Anderson.

James Anderson, 45, ship carpenter, was indicted for the murder of his wife. Prisoner was of intemperate habits, and often quarrelled with his wife. The evening of the murder the two appeared to be on exceptionally amicable terms, but at about 8 p.m. the neighbours heard a disturbance, and it was found that the prisoner had killed his wife by cutting her throat, and had then inflicted a severe wound upon his own. It appears that he believed that his wife exerted a "spell power" over him, and could make him, even when he was away from her, do deeds that he would have shrunk from; that she tried to poison him with beetroot and onions; that others besides his wife were his enemies, and were trying to thwart him in every way, and were conspiring against him; and that for the last twenty years his relatives have regarded him as insane. He was found unfit to plead, and ordered to be detained during her Majesty's pleasure.-(Lord Trayner).-Scotsman, September 17th.

\section{AFTER-CARE ASSOCIATION.}

The annual meeting will be held on Monday, February 6th, 1899, at 72, Grosvenor Street, W., the residence of Sir Samuel Wilks, President of the Royal College of Physicians, who will preside. The past year has been, we are informed, by far the most successful one in the annals of the Association, both in the number of cases assisted and in the amount of the subscriptions. Unfortunately the subscription of 650 , promised by Mr. Mocatta if 61000 were raised during the year, cannot be claimed.

The active assistance of the Medical Superintendents of Asylums is earnestly sought: many have long given it the most energetic support, but it is hoped that the increased means and experience of the Association will enable it to deal even more satisfactorily with the cases in future entrusted to it than it has done in the past. 